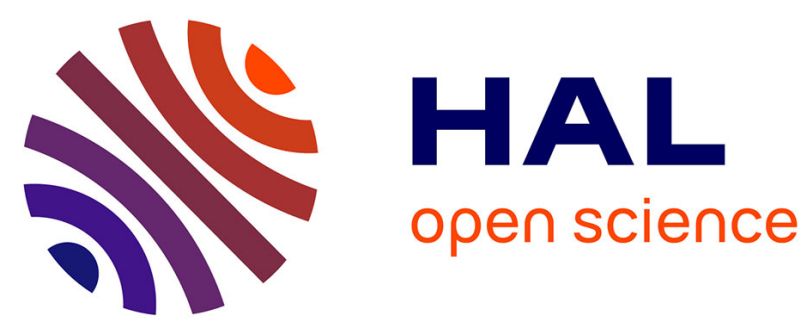

\title{
Thermoreversible Gelation of a Vinylidene Fluoride-Based Copolymer in Methyl Ethyl Ketone: Dynamics and Structure
}

Jessica Link, Olivier Sanséau, Mathieu Tauban, Frédéric Colbeau-justin, Cédric Lorthioir, Paul Sotta

\section{To cite this version:}

Jessica Link, Olivier Sanséau, Mathieu Tauban, Frédéric Colbeau-justin, Cédric Lorthioir, et al.. Thermoreversible Gelation of a Vinylidene Fluoride-Based Copolymer in Methyl Ethyl Ketone: Dynamics and Structure. Macromolecular Symposia, 2019, 385 (1), pp.1800162, 1-6. 10.1002/masy.201800162 . hal-02264495

\section{HAL Id: hal-02264495 \\ https://hal.sorbonne-universite.fr/hal-02264495}

Submitted on 26 Aug 2019

HAL is a multi-disciplinary open access archive for the deposit and dissemination of scientific research documents, whether they are published or not. The documents may come from teaching and research institutions in France or abroad, or from public or private research centers.
L'archive ouverte pluridisciplinaire HAL, est destinée au dépôt et à la diffusion de documents scientifiques de niveau recherche, publiés ou non, émanant des établissements d'enseignement et de recherche français ou étrangers, des laboratoires publics ou privés. 


\title{
Thermoreversible Gelation of a Vinylidene Fluoride-Based Copolymer in Methyl Ethyl Ketone: Dynamics and Structure
}

\author{
Jessica Link, Olivier Sanseau, Mathieu Tauban, Frédéric Colbeau-Justin, Cédric Lorthioir, \\ and Paul Sotta*
}

Thermoreversible poly(vinylidene fluoride-co-hexafluoropropylene) (P(VDF-coHFP)) gels are formed in an aliphatic ketone - methyl ethyl ketone (MEK) at high concentrations (above $11 \mathrm{wt} \%$ ). This gelation phenomenon is first investigated in terms of gelation kinetics which is found to depend strongly on both copolymer concentration and temperature. Melting temperatures $T_{\mathrm{m}}$ of P(VDF-co-HFP)-based gels prepared at different concentrations, in MEK are measured by DSC. Combination of ${ }^{19} \mathrm{~F}$ Nuclear Magnetic Resonance (NMR), Small-Angle X-ray Scattering (SAXS), and Wide-Angle X-ray Scattering (WAXS) on undried/nonlyophilized gels is used to probe both the gelation mechanisms and the structure of these systems. ${ }^{19} \mathrm{~F}$ NMR experiments allow studying selectively the fluorinated copolymer. The occurrence of a polymer network-like structure with rigid zones acting as cross-links has been highlighted. Such a behavior is only observed in the gel state: no polymer network or rigid zones exist when the polymer-solvent system is in the liquid state. Moreover, the fraction of rigid zones as well as the fraction of elastically active chain portions increases with the copolymer concentration. The nature, of the rigid zones present within the gels are investigated by $X$ ray diffraction. Rigid regions are found to display a crystalline order. combination of properties. ${ }^{[1-3]}$ Among this class of polymers, poly(vinylidene fluoride) (PVDF) and the VDF-based copolymers such as P(VDF-co-hexafluoropropylene) (P(VDF-co-HFP)) are emerging (co)polymers because of their high dielectric constant and their piezoelectric and pyroelectric properties. ${ }^{[4]}$ These (co)polymers show a complex semi-crystalline structure and are known to exist in up to five different crystal structures that have been widely studied by X-ray diffraction in the bulk state $^{[5-10]}$ The predominant crystalline phase is the $\alpha$ apolar polymorph, generally obtained under melt crystallization. However, the polar $\beta$-phase attracts technological interest as it accounts for the piezoelectric and pyroelectric properties of the polymer.

It has been found that PVDF and VDFbased copolymers form thermoreversible gels in certain solvents, the morphologies of which strongly depend on the exact nature of the solvent. ${ }^{[7,11-14]}$ It is generally agreed that thermoreversible gelation is the result of the formation of a three-dimensional network in which the junction points

\section{Introduction}

In recent years, fluorinated polymers have become very attractive systems due to their versatility (thermoplastics, elastomers, plastomers that can be semicrystalline to amorphous) and their

J. Link, O. Sanseau, M. Tauban, P. Sotta

LPMA

Solvay-CNRS UMR 5268

Saint-Fons, France

E-mail: paul.sotta-exterieur@solvay.com

F. Colbeau-Justin

Solvay R\&I

Aubervilliers, France

C. Lorthioir

Sorbonne Université

CNRS

Collège de France

Laboratoire de Chimie de la Matière Condensée de Paris

LCMCP, 75005 Paris, France

DOI: $10.1002 /$ masy.201800162 consist in physical bonds. ${ }^{[15-17]}$ Depending on the studied system, these physical bonds may result from hydrogen bonds, crystalline zones, or liquid-liquid phase separation. ${ }^{[18]}$

For PVDF in $\gamma$-butyrolactone, ${ }^{[19]}$ liquid-liquid phase separation has been considered as the cause of the gelation. ${ }^{[20]}$ Investigations of PVDF gels formed in other solvents (aromatic diesters, acetophenone, ethyl benzoate, glyceryl tributyrate) have shown that crystallization may be responsible for the PVDF gelation. ${ }^{[12,14,21]}$ These studies have also highlighted that the morphology of the PVDF gels strongly depends on the nature of the solvent. ${ }^{[13]}$ Kinetic studies of the gelation process have been performed in MEK and in others solvents to understand the gelation mechanism both from a macroscopic and a microscopic point of view. Ohkura et al. ${ }^{[22]}$ expressed the gelation rate, defined as the inverse of the gelation time $t_{\text {gel }}$ measured by a tube tilting method, as a product of a concentration-dependent factor $f$ $(C)$ and a temperature-dependent factor $g(T)$ :

$1 / t_{g e l} \propto f(C) g(T)$ 
PVDF gels were prepared in the concentration range 1-30 wt $\%$ and gelation kinetics in MEK was studied as a function of polymer concentration by using the tube-tilting method. In another set of measurements, the effect of temperature on the gelation kinetics was probed in the temperature range -40 to $-20{ }^{\circ} \mathrm{C}$ for concentrations in the range $17-30 \mathrm{wt} \% .^{[23]}$

Thus, the gelation of semi-crystalline polymers is a complex phenomenon and the nature of the gel depends on the polymer chain structure and molecular weight as well as on the nature of the solvent, or more precisely on polymer-solvent interactions. However, note that the structure, morphology and thermal behavior of these gels have mostly been studied in the dried state, considering that the morphology of the dried material is representative of the structure of the gel in the presence of solvent. ${ }^{[14,21]}$

In this paper, we report the thermoreversible gelation of a $\mathrm{P}(\mathrm{VDF}-\mathrm{co}-\mathrm{HFP})$ copolymer in methyl ethyl ketone (MEK). The kinetics of gelation is investigated, while a combination of

${ }^{19} \mathrm{~F}$ NMR, SAXS and WAXS experiments performed on the gels in the presence of solvent were used to probe the gelation mechanism and the structure of these systems.

\section{Experimental Section}

\subsection{Samples}

The poly(VDF-co-HFP) copolymer considered in this work (Figure 1) was provided by SOLVAY. The solvent, methyl ethyl ketone (MEK; Sigma Aldrich, France), was used as received. It has a boiling point of about $79^{\circ} \mathrm{C}$ at room pressure.

\subsection{Sample Preparation}

Solutions of $\mathrm{P}(\mathrm{VDF}-\mathrm{co}-\mathrm{HFP})$ at different concentrations were prepared by dissolving appropriate amounts of the copolymer in MEK under reflux at $60^{\circ} \mathrm{C}$ and stirring with a magnetic bar at $500 \mathrm{rpm}$ for $2 \mathrm{~h}$ in order to obtain homogeneous solutions. The solutions are cooled to room temperature in sealed vials and are then placed in an oil bath at a given temperature until the gel state is reached.

\subsection{Gelation Kinetics}

The kinetic study of the gelation process was carried out using a tube-tilting method in $24 \mathrm{~mm}$ diameter vials. The gelation time is considered as the time at which no flow of the sample is observed when the tube is tilted depending on the samples, the range of durations investigated stands between about $2 \mathrm{~min}$ and about 1 month.

\subsection{Differential Scanning Calorimetry}

DSC data were acquired on a TA Instruments Q2000 calorimeter at a heating rate of $1^{\circ} \mathrm{C} \min ^{-1}$. Hermetic pans were filled with 5$15 \mathrm{mg}$ of gel samples at $20^{\circ} \mathrm{C}$ and let equilibrating for $20 \mathrm{~min}$.

Only the first heating scan between 20 and $60^{\circ} \mathrm{C}$ was considered throughout this work.

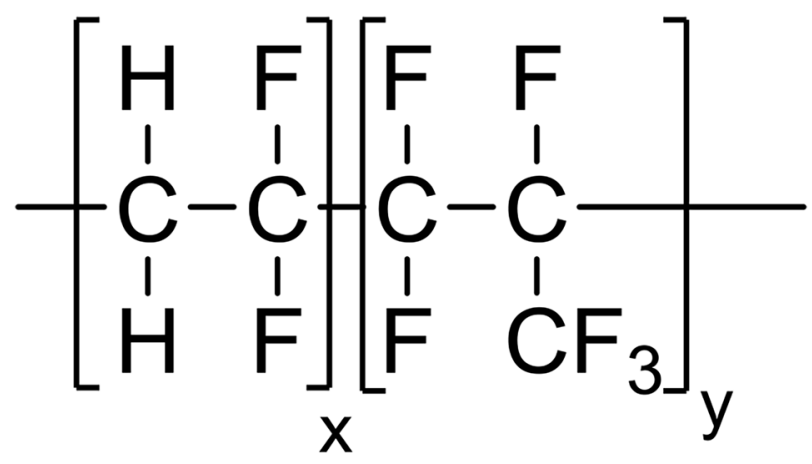

Figure 1. Chemical structure of P(VDF-co-HFP). y stands below $20 \%$.

\subsection{Wide-Angle X-Ray Scattering}

WAXS measurements were carried out at the Henri Longchambon Diffractometry Center (University of Lyon, France) on a D8 Bruker $\theta-2 \theta$ diffractometer using the $\mathrm{Cu} \mathrm{Ka}$ line (wavelength $\lambda=0.154 \mathrm{~nm}$ ). The gel sample was inserted into a glass capillary. A P(VDF-co-HFP) film sample, obtained by solvent casting a P(VDF-co-HFP)-MEK solution, was also investigated for comparison. The scattering intensities were measured using an angular range $(2 \theta)$ from $10^{\circ}$ to $45^{\circ}$, a resolution of $0.02^{\circ}$ and a measurement time of $75 \mathrm{~min}$.

\subsection{Small-Angle X-Ray Scattering}

SAXS measurements were performed at the SWAXS laboratory (IRAMIS, Saclay, France) equipped with a 2D detector. The acquisition time is $15 \mathrm{~min}$. The $q$ range investigated extends from $10^{-2}$ to $5 \AA^{-1}$. Samples were placed in a cell located in between two thin Kapton windows. The sample thickness was kept to about $1 \mathrm{~mm}$.

\section{7. ${ }^{19} \mathrm{~F}$ NMR}

Time domain ${ }^{19} \mathrm{~F}$ NMR measurements were carried out at the Institut de Chimie et des Matériaux de Paris Est (ICMPE, Thiais, France) on a $400 \mathrm{MHz}$ Bruker Avance III NMR spectrometer and a $4 \mathrm{~mm}$ MAS triple-resonance ${ }^{1} \mathrm{H} /{ }^{19} \mathrm{~F} / \mathrm{X}$ probe. Gels were inserted into $4 \mathrm{~mm} \mathrm{ZrO}_{2}$ CRAMPS rotors with a Boron Nitride cap. All measurements were performed under static conditions. Polyethylene spacers were used to center the sample within the coil. The $90^{\circ}\left({ }^{19} \mathrm{~F}\right)$ pulse length was $5.7 \mathrm{~ms}$ and the recycle delay, adjusted according to the longest $T_{1}\left({ }^{19} \mathrm{~F}\right)$ value, was set to $3 \mathrm{~s}$.

\section{Results and Discussion}

\subsection{Gelation Kinetics}

As a first approach to investigate the gelation mechanisms, the gelation time $t_{\text {gel }}$ was estimated using the tube-tilting method. Figure 2 shows the evolution of the gelation rate $1 / t_{\text {gel }}$ of PVDFco-HFP/MEK solutions as a function of concentration at various 


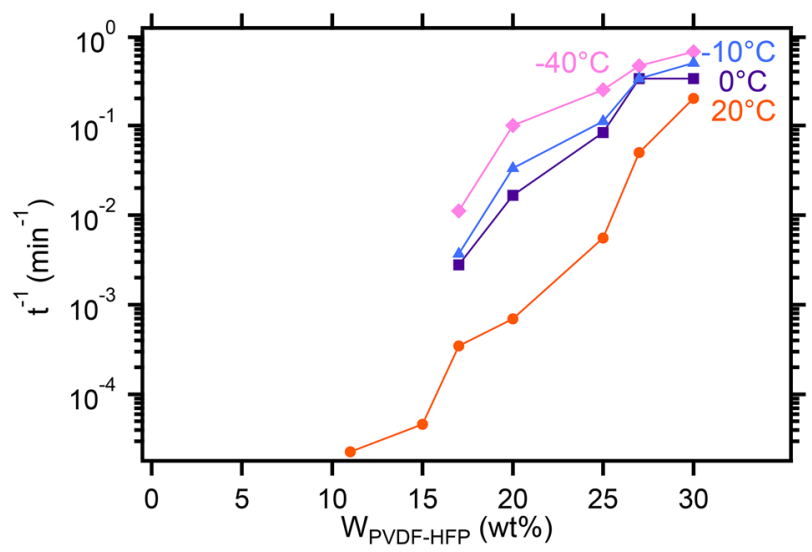

Figure 2. Gelation rate $1 / t_{\text {gel }}$ versus concentration for $\mathrm{P}(\mathrm{VDF}-\mathrm{co}-\mathrm{HFP})$ in solution in MEK measured for temperatures ranging between -40 and $20^{\circ} \mathrm{C}$.

temperatures. Below a critical concentration, which amounts to $11 \mathrm{wt} \%$ of $\mathrm{P}$ (VDF-co-HFP) at $20^{\circ} \mathrm{C}$, it is considered that gelation does not occur over one month (and gelation time is then considered to be infinite). Gelation rate measurements for concentrations below this value are not reported in the figure. It is clear that the gelation rate is highly dependent on both gelation temperature and copolymer concentration. At a given temperature, the gelation rate increases drastically as the concentration of P(VDF-co-HFP) increases.

Depending on the nature of the polymer and on the interactions between the polymer and the solvent, different gel structures, corresponding to different types of threedimensional network, may be formed from polymer-solvent solutions: a network resulting from the formation of strong, persistent molecular interactions, such as for example multiple hydrogen bondings; a liquid-liquid phase separation leading to a percolating polymer-rich network; or a network with junction points composed of crystalline zones. Thus, structural studies are necessary to elucidate the nature of effective junction points and the structure of the P(VDF-co-HFP) gels.

\subsection{Thermal Behavior of the Gels}

$\mathrm{P}($ VDF-co-HFP)/MEK solutions are converted to gels on cooling and turn back to low-viscosity solutions on heating. The sol-gel transition is thus thermoreversible. As seen above, the gelation behavior of this copolymer is highly dependent on both polymer concentration and temperature. DSC experiments were performed to investigate whether structural and/or thermodynamical changes occur at the sol-gel transition. From a macroscopic point of view, once formed, all gels transform into a fluid in a similar range of temperature, between 40 and $45^{\circ} \mathrm{C}$, and no systematic dependence on the concentration was detected.

DSC thermograms during the first heating scan are shown in Figure 3 for gels with various copolymer concentrations. A weak endothermic peak systematically appears at a temperature $T_{m}$ in between 40 and $50^{\circ} \mathrm{C}$. This range of temperature matches with the sol-gel transition of the P(VDF-co-HFP)/MEK systems. This endothermic peak is not due to solvent evaporation, as the

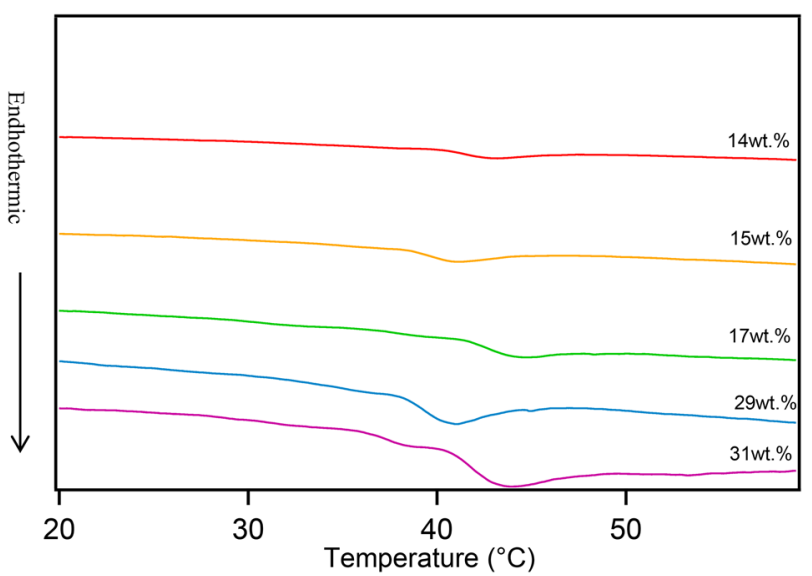

Figure 3. $D S C$ thermograms of $P(V D F-c o-H F P) / M E K$ gels with various $\mathrm{P}(\mathrm{VDF}-\mathrm{co}-\mathrm{HFP})$ concentrations.

boiling temperature of the solvent is close to $80^{\circ} \mathrm{C}$ and DSC measurements were performed using hermetic pans. The melting temperature $T_{m}$ varies from 41 to $44^{\circ} \mathrm{C}$ and does not follow a systematic variation with the gel concentration. In contrast, the melting enthalpy increases as the concentration of the copolymer in the gel increases. The DSC results suggest that crystallites are present in the gels. Therefore, the gelation of $\mathrm{P}(\mathrm{VDF}-\mathrm{co}-\mathrm{HFP})$ in MEK is due to the formation of crystalline zones of the copolymer in the gels. These crystalline regions might then be bridged by portions of chains in solution to form a three-dimensional network characteristic of the gel state.

The percentage of crystalline zones in the different gels may be determined from DSC thermograms using the following equation:

$X_{c}=\frac{\Delta H_{m}}{\Delta H_{m}^{0}} \times 100(\%)$

where $\Delta H_{m}$ is the heat of fusion measured in the P(VDF-coHFP) gels, normalized to take into account the mass of the copolymer in the gel. $\Delta H_{m}^{0}$ stands for the enthalpy of melting for a $100 \%$ crystalline material. The value $\Delta H_{m}^{0}=104.7 \mathrm{Jg}^{-1}$, reported for PVDF, was considered here. ${ }^{[24}$ Using this approach, the mass fractions of crystalline zones referred to the total mass of P(VDF-co-HFP)/MEK gels was found to range between 0.3 and $0.7 \%$, depending on the copolymer concentration. Referred to the amount of P(VDF-co-HFP) copolymer, it would correspond to a crystallized fraction of the order $2.5 \%$.

\subsection{Gel Structure}

DSC experiments indicated that a small fraction of crystalline zones, which may act as effective junction points, are present in the gels and melt in a similar temperature range as the one characterizing the gel-sol transition. To further validate this result, WAXS measurements were performed, on copolymer/ MEK gels. The WAXS pattern of a P(VDF-co-HFP)/MEK gel with a copolymer concentration of $20 \mathrm{wt} \%$ is shown in Figure 4. For the sake of comparison, the diffractogram measured on bulk 


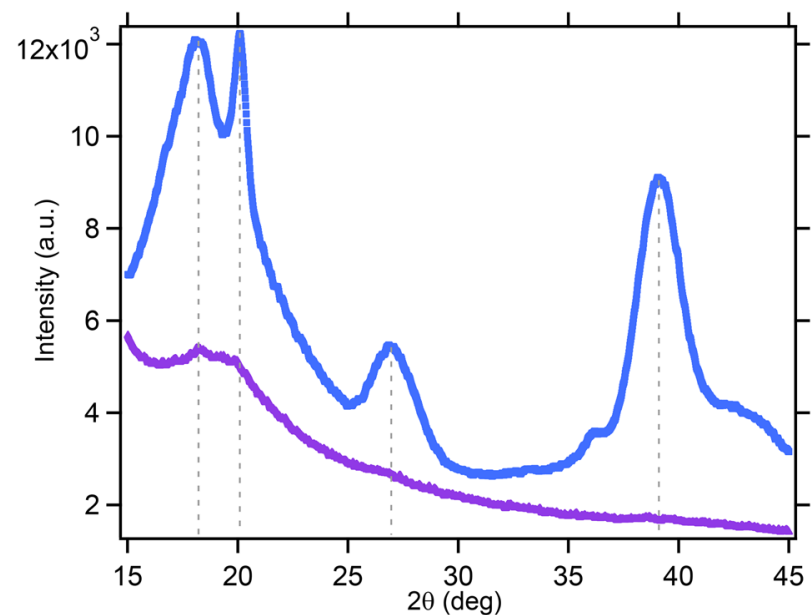

Figure 4. WAXS patterns of a $\mathrm{P}(\mathrm{VDF}-\mathrm{co}-\mathrm{HFP}) / \mathrm{MEK}$ gel with a composition $W_{P(V D F-c o-H F P)}=20 w t \%(\triangle$, bottom curve) and a neat $\mathrm{P}($ VDF-co-HFP) film ( $\square$, top curve), used as a reference.

P(VDF-co-HFP) was also included. For this latter WAXS pattern, the main diffraction peaks observed at $2 \theta=18.07^{\circ}$ (corresponding to $100 / 020$ families of planes), $20.10^{\circ}$ (110 planes), $26.86^{\circ}$ (021 planes), and $39.06^{\circ}$ (131 planes) are similar to the ones detected for the $\alpha$ phase (Form II) of neat PVDF. ${ }^{[4]}$ Interestingly, the WAXS pattern for the P(VDF-co-HFP) gel in MEK shows tiny but significant peaks at $2 \theta$ positions corresponding exactly to the main peaks observed on neat P(VDF-co-HFP). Besides, though tiny, these Bragg peaks are not detected on the WAXS measurements determined on a sample in the liquid state (data not shown). This result confirms the presence of crystalline zones in the gels. The gelation of the P(VDF-co-HFP) copolymer in MEK results from the formation of crystalline zones, which do not exist in the liquid state. Analyzing WAXS data quantitatively involves some difficulties. First, the (potentially) reduced size of the crystalline regions should induce a significant broadening of the corresponding peaks, making them again more difficult to be observed. Second, there is a large contribution from the solvent and/or amorphous part of the sample. Therefore, the intensities of the crystalline peaks relative to the amorphous background cannot be safely used to quantify the degree of crystallinity or to estimate the apparent crystallite size for this gel.

\subsection{Polymer Dynamics in the Gel}

In combination to the structural study by WAXS, NMR was used to investigate the segmental dynamics of $\mathrm{P}(\mathrm{VDF}-\mathrm{co}-\mathrm{HFP})$ chains in MEK solutions and gels at different concentrations. This copolymer is predominantly fluorinated while the solvent is hydrogenated. Therefore, fluorine NMR $\left({ }^{19} \mathrm{~F}\right.$ NMR) allowed observing selectively the signal from the polymer in solution. Note that, due to the large range of chemical shifts (more than $110 \mathrm{ppm}$ ) of fluorine (as compared, e.g., to protons) which may potentially lead to irradiation bias, all reported time-domain NMR signal intensities were collected by Fourier transforming the observable decay after the considered pulse sequence and integrating the most intense peak, corresponding to the fluorine atoms in the $-\mathrm{CF}_{2}$ - groups, which was set at the center of the spectra.

Transverse relaxation measurements using standard Hahn echo sequences were first performed. Note that chemical shifts are refocused in the Hahn echo sequence. Transverse relaxation curves obtained in a P(VDF-co-HFP) solution and in gels in MEK with different weight fractions of polymer ( $\left.\mathrm{W}_{\mathrm{P}(\mathrm{VDF}-\mathrm{co}-\mathrm{HFP})}\right)$ are shown in Figure 5. The relaxation becomes faster as the polymer concentration in the solution or gel increases, indicating that the dynamics of the polymer becomes more and more affected. The overall dynamics remain in the fast motion regime, as the overall average relaxation times remain long, in the few tens of $\mathrm{ms}$ range. The dynamics seem to become more and more heterogeneous, as the relaxation curves deviate more and more from simple exponential shape. Besides, in gel systems a small fraction of the signal with a quite shorter relaxation time, corresponding to a small fraction of the overall polymer, can be qualitatively discriminated. This would correspond to a small fraction of the polymer having a significantly slower and/or restricted dynamics. This fraction is not present in the signal from the liquid system at lower concentration.

It is, however, impossible to assess the existence of rigid zones from these measurements only. In order to probe selectively a rigid fraction of the polymer, ${ }^{19} \mathrm{~F}$ double-quantum (DQ) NMR measurements were performed on polymer-solvent solutions and gels, using the five-pulse sequence for DQ coherence selection and observation, ${ }^{[25-27]}$ This sequence is far less efficient to refocus multi-spin dipolar interactions as compared to the one proposed by Baum and Pines, ${ }^{[25]}$ later improved by Saalwächter. ${ }^{[28]}$ However, it offers the possibility to probe the shorttime range of the DQ excitation process, below $100 \mathrm{~ms}$ typically. The DQ sequence used with short excitation/reconversion times $t_{D Q}$ acts as an effective filter to retain only those parts of the material with strong dipolar couplings between fluorine nuclei, that is, only the rigid parts. The amplitudes of the ${ }^{19} \mathrm{~F} D Q$ coherences for P(VDF-co-HFP)/MEK systems in the liquid or gel

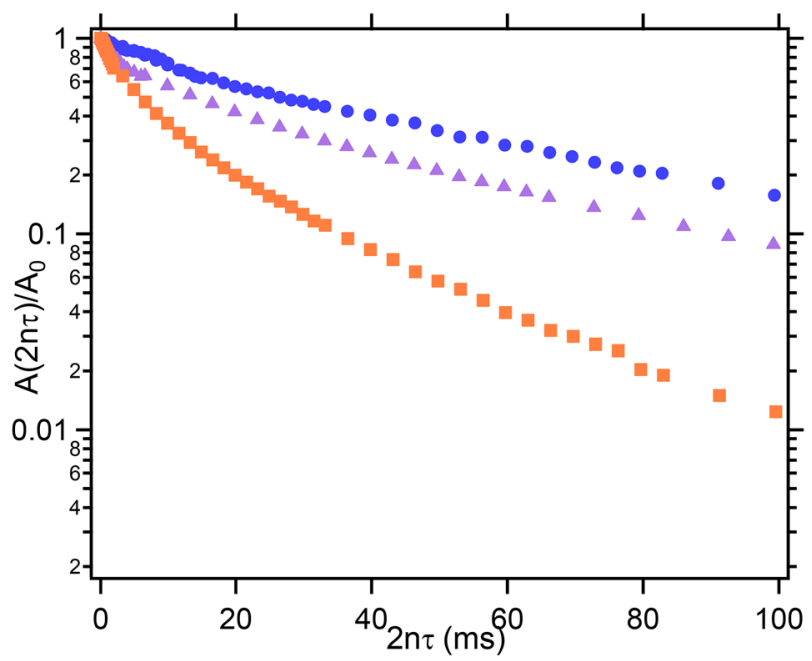

Figure 5. Transverse ${ }^{19} \mathrm{~F}$ NMR relaxation obtained with a Hahn echo sequence for a liquid solution of $\mathrm{P}(\mathrm{VDF}-\mathrm{co}-\mathrm{HFP})$ in MEK with $\mathrm{W}_{\mathrm{P} \text { (VDF-co- }}$ $H F P)=0.11$ (blue $\bullet$ ) and for P(VDF-co-HFP) - MEK gels: $\Delta$ (violet): $W_{P(\text { VDF-co-HFP })}=0.2 ; \square($ red $): W_{P(\text { VDF-co-HFP })}=0.3$. 


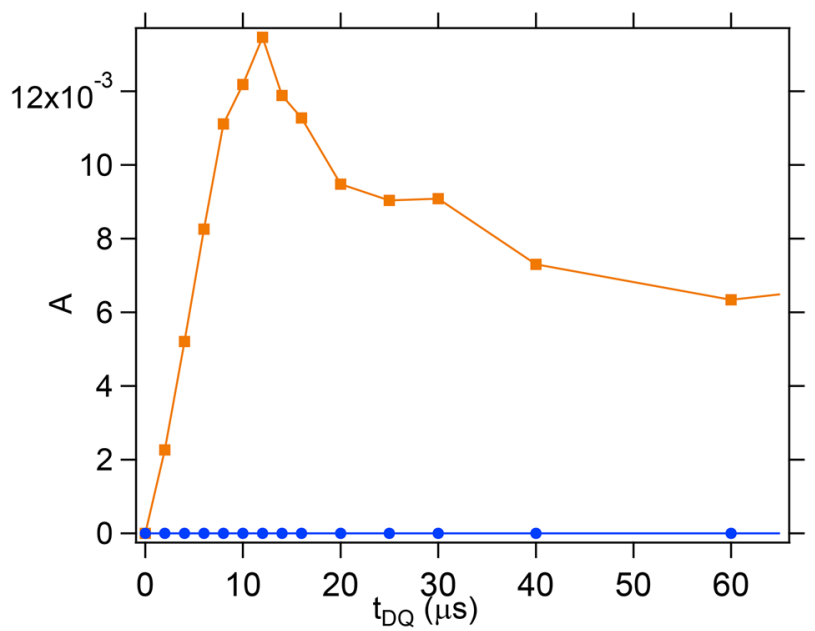

Figure 6. DQ signal obtained after a 5-pulse Baum and Pines sequence ${ }^{[25]}$ as a function of the $D Q$ excitation/reconversion time in the sequence, in a liquid $\mathrm{P}(\mathrm{VDF}-\mathrm{co}-\mathrm{HFP})$ solution in MEK with $\mathrm{W}_{\mathrm{P}(\mathrm{VDF}-\mathrm{co}-\mathrm{HFP})}=0.11$ (blue $\bullet$ ) and in a $\mathrm{P}(\mathrm{VDF}-\mathrm{co}-\mathrm{HFP})-\mathrm{MEK}$ gel with $\mathrm{W}_{\mathrm{P} \text { (VDF-co-HFP) }}=0.30$ (orange $\square$ ). The amplitude of the signal was normalized by the initial transverse relaxation amplitude.

states are shown Figure 6 as a function of the DQ excitation time $t_{D Q}$. In the liquid solution with $11 \mathrm{wt} \% \mathrm{P}(\mathrm{VDF}-\mathrm{co}-\mathrm{HFP})$, no DQ signal is observed, meaning that no rigid fraction of the polymer is present. Conversely, in the gel with $30 \mathrm{wt} \% \mathrm{P}(\mathrm{VDF}-\mathrm{co}-\mathrm{HFP})$, a non-zero ${ }^{19} \mathrm{~F}$ DQ signal is clearly detected, which proves that a fraction of the polymer chain segments are frozen or have strongly restricted motions. Moreover, the ${ }^{19} \mathrm{~F} \mathrm{DQ}$ build-up curve shows a maximum for $t_{D Q} \cong 12 \mu \mathrm{s}$. The static value $D_{\text {stat }}$ of the apparent ${ }^{19} \mathrm{~F}-{ }^{19} \mathrm{~F}$ dipolar couplings for the vicinal fluorines of the backbone $\mathrm{CF}_{2}$ groups, which are the major types of fluorine present in our $\mathrm{P}(\mathrm{PDV}$-co-HFP) copolymer, are was recently calculated for Nafion and a value $16.06 \mathrm{kHz}$ was obtained. ${ }^{[29]}$ Interestingly, the value $\left(2 \pi \times D_{\text {stat }}\right)^{-1} \approx 10 \mu$ s is very close to the $t_{D Q}$ at the maximum of the ${ }^{19} \mathrm{~F}$ DQ build-up curve. Therefore, these experiments indicate that for the gel with $30 \mathrm{wt} \% \mathrm{P}(\mathrm{VDF}$ co-HFP), some copolymer units are found to be immobile over the tens of microsecond time scale.

From a semi-quantitative point of view, the fraction of strongly dipolar coupled fluorine, that is, to the rigid fraction of P(VDFco-HFP) units in the gels, may be roughly estimated from the ${ }^{19} \mathrm{~F}$ DQ signal intensity. For this purpose, the DQ signal was normalized to the overall initial intensity of the corresponding transverse relaxation signal. The measured amplitude at the maximum of the build-up curve is of order $1.4 \%$. The DQ conversion efficiency generally observed for rigid organic compounds typically ranges between 20 and $30 \%$. One may thus consider that roughly $5-7 \%$ of the copolymer units would be involved in crystallites, which is in rather good qualitative agreement with DSC results shown above. Therefore, ${ }^{19} \mathrm{~F}$ NMR confirms that a small fraction of P(VDF-co-HFP) forms rigid zones in systems which have undergone gelation. These rigid zones may be identified with crystalline zones observed through DSC and WAXS with a high degree of certainty.

Crystalline zones present in the gel state should be exclusively composed of VDF and HFP units, by contrast the surrounding

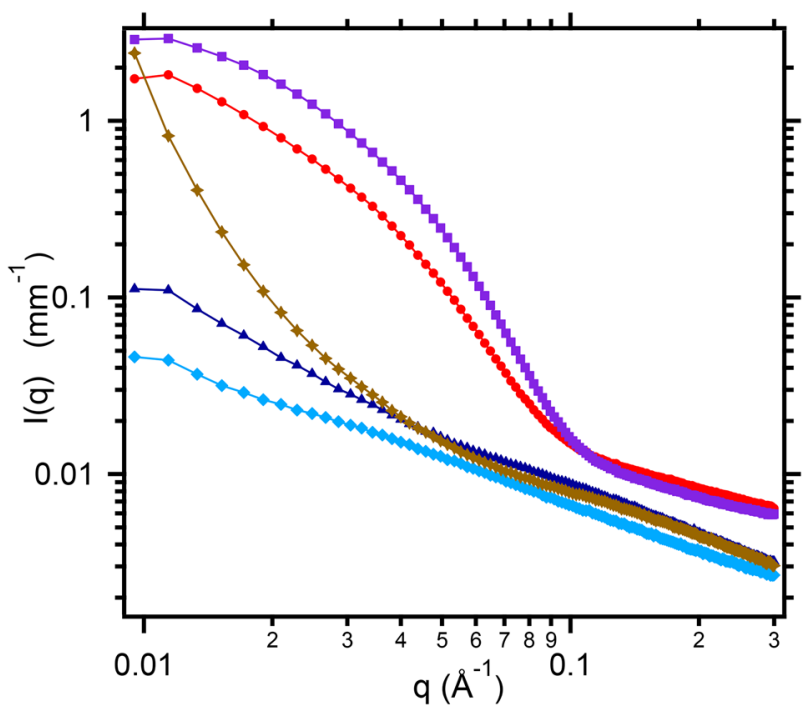

Figure 7. Normalized SAXS profiles for P(VDF-co-HFP)/MEK systems of different compositions: (light blue): $\mathrm{W}_{\mathrm{P}(\mathrm{VDF}-\mathrm{co}-\mathrm{HFP})}=4 \mathrm{wt} \%$; $($ (blue): $W_{P(\text { VDF-co-HFP })}=13 \mathrm{wt} \% ; \diamond$ (brown): $W_{P(\text { VDF-co-HFP })}=15 \mathrm{wt} \% ;$ $W_{P(V D F-c o-H F P)}=20 w t \%$; (violet): $W_{P(V D F-c o-H F P)}=26 \mathrm{wt} \%$. The systems with $\mathrm{W}_{\mathrm{P}(\mathrm{VDF}-\mathrm{co}-\mathrm{HFP})}=20$ and $26 \mathrm{wt} \%$ were in the gel state.

medium corresponding to a copolymer/solvent mixture, with a predominant fraction of solvent. As the electron density of the fluorinated copolymer and the one of the solvent are significantly different (electron density difference of about $2.3 \times 10^{20}$ electrons $/ \mathrm{mm}^{3}$ ), the $\mathrm{P}(\mathrm{VDF}-\mathrm{co}-\mathrm{HFP}) / \mathrm{MEK}$ gels should give rise to a characteristic SAXS profile. Thus, SAXS experiments were performed to confirm this feature. The scattered intensities measured for P(VDF-co-HFP)/MEK mixtures at different concentrations are shown in Figure 7. In liquid solutions Below the sol-gel transition (4 and $13 \mathrm{wt} \%$ of P(VDF-co-HFP)), the small-angle scattering pattern is typical of a single-phase polymer-solvent mixture. The scattering intensity starts increasing at small angle in the system with $15 \mathrm{wt} \%$ of $\mathrm{P}(\mathrm{VDF}-\mathrm{co}-\mathrm{HFP})$, which is very close to the gel point. Above the sol-gel transition (gels corresponding to 20 and $26 \mathrm{wt} \%$ of P(VDF-co-HFP) in Figure 7), a large additional scattering appears for $q$ values below $0.1 \AA^{-1}$ typically. This feature indicates the presence of heterogeneities in a range of characteristic size between 6 and $60 \mathrm{~nm}$. The scattering intensity at low $q$ values increases as the polymer concentration is raised up while keeping essentially the same shape. The general shape of the SAXS curves would rather correspond to anisotropic objects like platelets or tubules, with a significant polydispersity.

\section{Conclusion}

Solutions of a fluorinated copolymer, P(VDF-co-HFP), in MEK have been investigated. P(VDF-co-HFP) forms thermoreversible gels in MEK with gelation kinetics that strongly depend on both concentration and temperature. A combination of experimental approaches has been used to understand the gelation dynamics and the structure of the P(VDF-co-HFP) gels in MEK. DSC measurements on gels evidence an endothermic 
peak that might correspond to the melting of crystalline zones, this thermal event being concomitant with the thermally induced gel $\rightarrow$ sol transition. WAXS patterns obtained on the gels confirm the presence of a tiny fraction of crystallites. ${ }^{19} \mathrm{~F}$ NMR was used to observe selectively the fluorinated copolymer and confirms that rigid zones are formed when the $\mathrm{P}$ (VDF-co-HFP) in MEK reaches a gel state, while such regions do not occur in the liquid state. The fraction of rigid zones in the gel state increases as the polymer concentration is raised up. Gels also exhibit a characteristic small-angle scattering profile which is absent in the liquid state, indicative of the presence of heterogeneities at typical sizes ranging between 6 and $60 \mathrm{~nm}$.

\section{Acknowledgements}

We thank R. Vera at the Henri Longchambon Diffractometry Center, University of Lyon, France for performing the WAXS experiments and O. Taché at the SWAXS laboratory, Saclay, France for performing the SAXS experiments.

\section{Keywords}

crystallization, fluorine NMR, methyl ethyl ketone, poly(vinylidene fluoride-co-hexafluoropropylene), thermoreversible gelation

[1] H. L. Jackson, J. Polym. Sci. B: Polym. Lett. 1972, 10, 316.

[2] R. A. Pethrick, Br. Polym. J. 1988, 20, 533.

[3] B. Ameduri, Chem. Rev. 2009, 109, 6632.

[4] E. M. C. A. R. V. Tomer, J. Appl. Phys. 2011, 110, 044107.
[5] P. Martins, A. C. Lopes, S. Lanceros-Mendez, Prog. Polym. Sci. 2014, 39, 683.

[6] J. B. Lando, H. G. Olf, A. Peterlin, J. Polym. Sci. A-1: Polym. Chem. 1966, 4, 941.

[7] M. Tazaki, R. Wada, O. Abe Masaru, T. Homma, J. Appl. Polym. Sci. 1998, 65, 1517.

[8] R. Hasegawa, M. Kobayashi, H. Tadokoro, Polym. J. 1972, 3, 591.

[9] R. Hasegawa, Y. Takahashi, Y. Chatani, H. Tadokoro, Polym. J. 1972, 3,600 .

[10] M. Kobayashi, K. Tashiro, H. Tadokoro, Macromolecules 1975, 8, 158.

[11] M. Okabe, R. Wada, M. Tazaki, T. Homma, Polym. J. 2003, 35, 798.

[12] S. Mal, P. Maiti, A. K. Nandi, Macromolecules 1995, 28, 2371.

[13] S. Mal, A. K. Nandi, Langmuir 1998, 14, 2238.

[14] S. Mal, A. K. Nandi, Polymer 1998, 39, 6301.

[15] K. Kawanishi, M. Komatsu, T. Inoue, Polymer 1987, 28, 980.

[16] M. Komatsu, T. Inoue, K. Miyasaka, J. Polym. Sci. B: Polym. Phys. 1986, 24, 303.

[17] R. C. Domszy, R. Alamo, C. O. Edwards, L. Mandelkern, Macromolecules 1986, 19, 310.

[18] D. R. Paul, J. Appl. Polym. Sci. 1967, 11, 439.

[19] J. W. Cho, H. Y. Song, S. Y. Kim, Polymer 1993, 34, 1024.

[20] W. Cho Jae, W. Lee Gyu, J. Polym. Sci. B: Polym. Phys. 1996, 34, 1605.

[21] A. K. Dikshit, A. K. Nandi, Macromolecules 1998, 31, 8886.

[22] M. Ohkura, T. Kanaya, K. Kaji, Polymer 1992, 33, 5044.

[23] P. J. P. Yadav, G. Ghosh, B. Maiti, V. K. Aswal, P. S. Goyal, P. Maiti, J. Phys. Chem. B 2008, 112, 4594.

[24] Y. Rosenberg, A. Siegmann, M. Narkis, S. Shkolnik, J. Appl. Polym. Sci. 1991, 43, 535.

[25] J. Baum, A. Pines, J. Am. Chem. Soc. 1986, 108, 7447.

[26] C. Lorthioir, M. Khalil, V. Wintgens, C. Amiel, Langmuir 2012, 28, 7859 .

[27] M. Munowitz, A. Pines, Adv. Chem. Phys. 1987, 66, 1.

[28] K. Saalwächter, Modern Magnetic Resonance (Ed.: G.A. Webb), Springer International Publishing, Cham 2017.

[29] Z. B. Yan, D. H. Brouwer, G. R. Goward, Macromolecules 2016, 49, 7331. 